\title{
Iris sangrenta: arte como visão premonitória em Eyes of Laura Mars \\ (1978) e Sette note in nero (1977)
}

Letícia Badan Palhares Knauer de Campos ${ }^{1}$

DOI 10.20396/eha.vil4.3461

O trânsito cinematográfico entre Itália e Estados Unidos nos revela uma aproximação fecunda de temas, olhares e abordagens, refletido assim por toda a história do cinema, mas presente sobretudo, no cinema popular e de gênero. John Carpenter - cineasta, roteirista, produtor e compositor - há muito confirmou a presença de Dario Argento em suas produções. É a partir dos gialli argentinanos e também Suspiria que nasce, por exemplo, o clássico slasher norte-americano Halloween (1978).

No mesmo ano em que lança seu filme-emblema, o auteur do horror é responsável pela história de uma inquietante produção thriller dos anos 1970, Eyes of Laura Mars (1978), realizado pelo diretor de The Empire Strikes Back (1980), Irvin Kershner. O filme concentra-se sob o ponto de vista de Laura Mars (Faye Dunaway), uma fotógrafa de moda residente em Nova York. Ela nutre-se de imagens de violência explícita para compor o repertório visual de sua obra. As cenas de homicídio, reveladas para ela em visões e sonhos, refletem-se na arquitetura elementar de sua fotografia, em que a moda, o corpo e o sangue manifestam-se como onda premonitória da inerte violência estética. Ao antever os assassinatos em premonições, a protagonista inicia um processo de investigação juntamente com a polícia, numa tentativa de encontrar nas imagens fragmentadas de seus delírios, a solução para os atos criminais. É John Neville (Tommy Lee Jones), o investigador responsável pelo caso, que aponta as semelhanças entre as composições fotográficas de Mars e a mise en scene do assassino. Personagem que posteriormente se revelará como o autor dos homicídios

O filme parte de uma história de escrita por Carpenter, cujo roteiro co-assina com David Ze$\operatorname{lag}^{2}$. A direção cai nas mãos de Kershner após a recusa de Lindsay Anderson devido ao teor erótico do filme. Visto pelo realizador de If.. (1968) como de baixo interesse. Embora a trama se assemelhe

\footnotetext{
1 Graduada em História com ênfase em História da Arte pelo IFCH/UNICAMP (2013). Mestra pelo IFCH/UNICAMP com a dissertação A cultura visual no cinema de Dario Argento, sob orientação do Prof. Dr. Jorge Coli e apoio FAPESP. Pesquisadora do CHAA - Centro de História da Arte e Arqueologia. Desenvolve atualmente uma pesquisa de doutorado em História da Arte, pelo Programa de Pós-Graduação em História do IFCH/UNICAMP, sob orientação do Prof. Dr. Jorge Coli, sob o título: "O imaginário visual do cinema de horror italiano". Lattes: http://lattes.cnpq $\mathrm{br} / 7927726147953517$

2 Com alterações de Irvin Kershner, Julian Barry, Mart Crowley e Joan Tewkesbury - sem créditos.
} 
a diversos thrillers americanos do mesmo período, algo parece destacar Eyes of Laura Mars dos demais. Carpenter insere em sua história uma trama que perpassa os artifícios genéricos dos whoduint americanos. A arte e a moda são elementos cruciais para a narrativa. Não se trata de apresentar a arte - fotográfica no caso - como um mero pano de fundo para os acontecimentos investigativos. Ela é estrutura fundamental para a trama e a estética do filme.

O corpus imagético de Laura remete diretamente às produções fotográficas dos anos 70, fruto direto de releituras de obras de Chris Von Wangenheim, Helmut Newton e Rebecca Blake. Suas imagens, como as de Mars, mesclam erotismo, fetichismo, morte e androginia. E têm como palco a selva urbana nova-iorquina, numa completa teatralização de beleza e horror. São reflexos modernos da selvageria feminina frente à fragilidade e submissão dos homens.

Blake realiza as fotografias que vemos na tela como aquelas de Mars. O catálogo de sua série Eyes of Laura Mars, cujas páginas são usadas por Neville em comparação aos assassinatos, é na realidade um catálogo fotográfico das obras de Helmut Newton. E para além do uso de imagens dele e Blake para a composição do imaginário estético de Laura, o filme conta também com a participação de duas importantes modelos da época, Lisa Taylor e Darlanne Fluegel, que posaram igualmente para os supracitados artistas.

São imagens de um erotismo pungente e deslumbrante. Tudo remete ao luxo, à ostentação, à sedução e ao sexo. As cenas privadas de crimes passionais caracterizam esse aspecto suntuoso da fotografia de Mars (Blake). A precisão calculada do instante fotográfico-criminal contempla-se no controle absoluto da cena. Requinte e ornamentação cercam o drama inerte em primeiro plano, cujo prazer se evidencia no todo. A cortina ao canto lembra a teatralidade da arte holandesa, ou ainda uma releitura trágica da Rolla, de Gervex. Pinturas de gênero maculadas pelos vícios modernos.

A fotografia não se faz como elemento passageiro da trama, antes, seu uso é complexo e atual. Enquanto serve à fotografia materializar o registro do evento premonitório, sua influência no imaginário estético é igualmente explorada. As premonições são a inspiração onírica de Mars, que como dito as usa para a composição do corpus visual de sua arte. O assassino (Neville), por outro lado, vê a arte de Mars como fonte inspirativa para os atos homicidas, a disposição dos corpos remete imediatamente às imagens da fotógrafa. A intenção de sua arte se concretiza como via de substanciação das fotografias de Mars. E como aquelas imagens que retratam um mundo de vícios e crimes passionais, a própria relação apresentada no filme, entre Laura e John parece retraçar esse jogo entre feminino e masculino, subjugação e dominação. É uma incorporação direta das características e temas das fotografias. Embora a questão da arte como inspiração para o assassinato tenha 


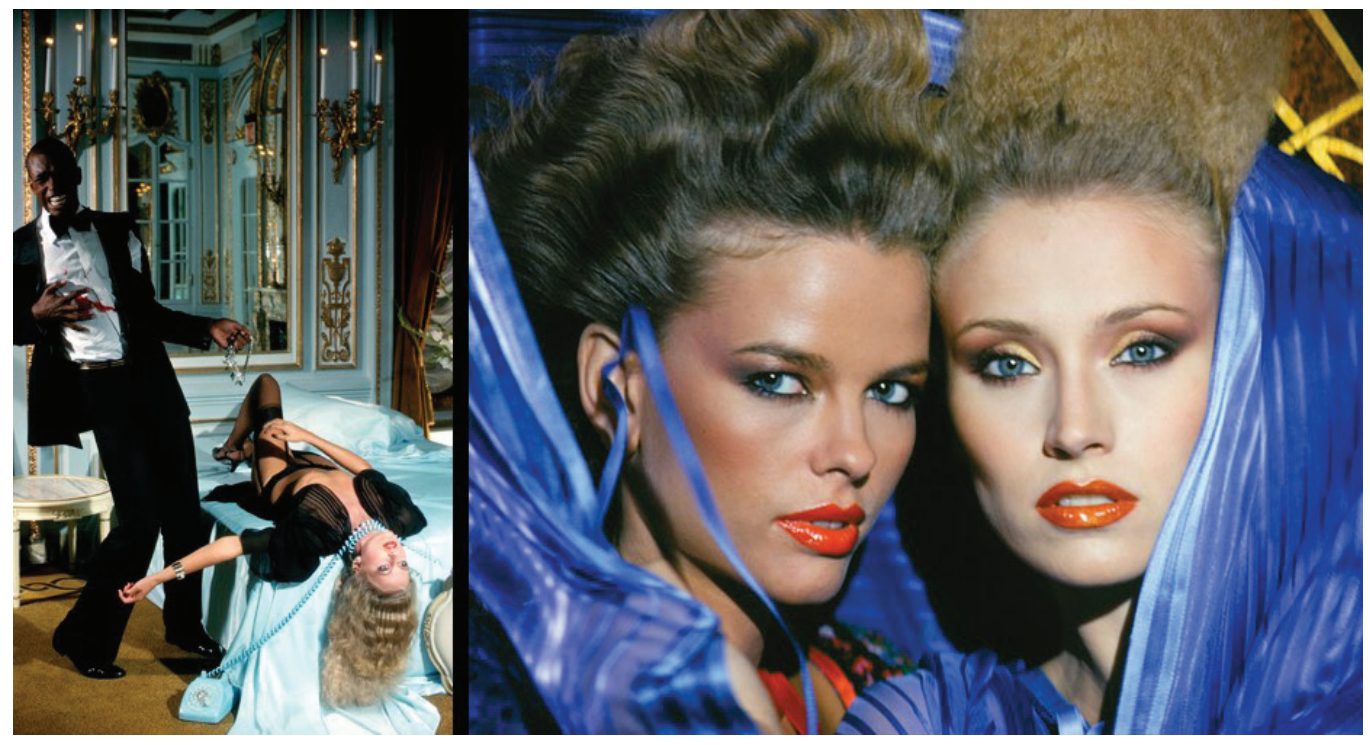

[Figura 01]

Fotografia de Rebecca Blake para Eyes of Laura Mars
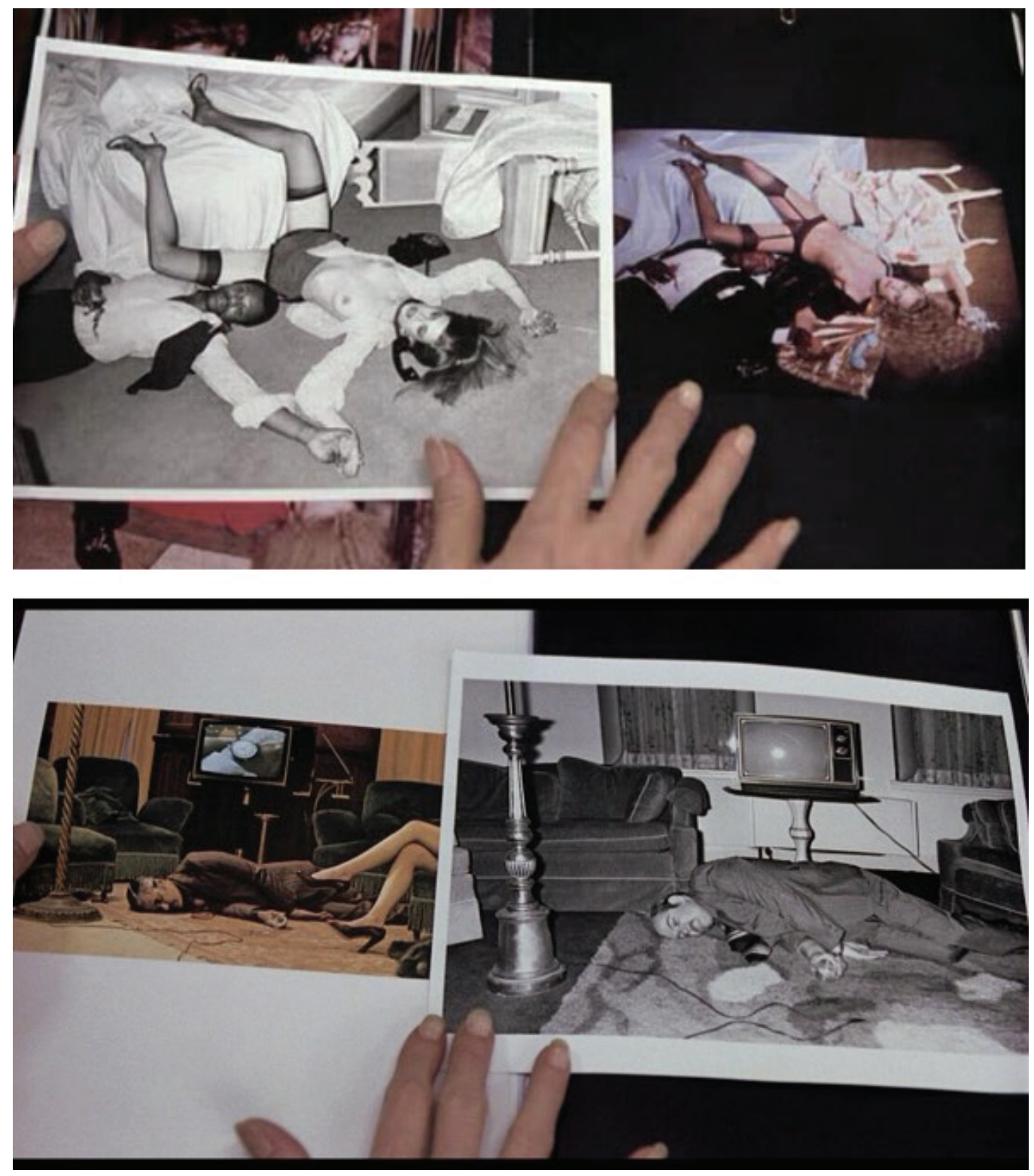

[Figura 02]

Fotogramas de Eyes of Laura Mars: comparação entre as fotografias de Laura e as fotografias forenses 
se apresentado em demasia na cultura³ , Eyes of Laura Mars condensa uma preocupação estética típica do cinema de gênero da Itália, fato que corrobora inclusive para as duras críticas que recebe na época de seu lançamento.

Em 1977, um ano antes de Eyes of Laura Mars, Lucio Fulci havia realizado o seu quarto filme de gênero giallo, Sette Note in Nero. Co-escrito com Roberto Gianviti e Dardano Sacchetti (que trabaIhara anteriormente com Dario Argento, cujos gialli obtiveram sucesso e popularidade na Itália) - o whodunit se emprega do tema da arte e da parapsicologia na busca pelo assassino.

Em Dover, na Inglaterra, no dia 12 de outubro de 1959 às 11h45 da manhã uma mulher dirige até o penhasco e suicida-se. No mesmo horário, na Piazza Michelangelo, em Florença, a jovem Virginia é acometida por uma visão da morte da mãe. Dezoito anos mais tarde, ao retornar do aeroporto local, onde despedia-se de seu marido, Francesco Ducci (Gianni Garko), Virginia (interpretada por Jennifer O’Neil) tem visões fragmentas de um assassinato. Um rádio-táxi amarelo; uma reprodução de uma pintura em preto e branco com uma inscrição sobre; um ícone bizantino; um aposento vermelho; uma carta revelada na base de um busto policromado; as pernas de um homem manco; e uma pessoa sendo emparedada viva.

Posteriormente, ao chegar à antiga residência da família de Francesco, na intenção de renovar o edifício, ela percebe que sua visão retratava exatamente o antigo quarto do marido. Ao quebrar a superfície da parede, tentando decifrar as imagens que vira em suas visões, Virgínia descobre um esqueleto no interno da parede. A sequência remete, por diversos motivos, à revelação do desenho por Marc (David Hemmings) nas paredes da villa del bambino urlante de Profondo Rosso. Após o aparecimento do corpo - que a polícia identifica como Agnese Bignardi, uma modelo desaparecida em 1972 - e da condenação de seu marido, Virginia inicia uma investigação paralela à polícia, juntamente com seu psiquiatra (Marc Porel) e a assistente, a fim de inocentar Francesco. O que ela encontra, no entanto, tal qual Mars revela mais sobre seu próprio destino.

Aqui a arte encontra um papel mais notório que a citação plástica. Ela é a chave que permite Virgínia trilhar os passos já traçados de seu destino. A arte se faz presente em suas premonições, são parte do processo investigativo que utiliza para descobrir o assassino e além e tudo remete a eventos reais do período. Os ícones de sua antevisão conformam um imaginário calçado na história

\footnotetext{
3 Na literatura isso se evidencia em O assassinato como uma das Belas Artes, de Thomas de Quincey (1835); no cinema a ideia do artista assassino aparece em filmes como A Bucket of Blood (1959), de Roger Corman, mas principalmente em Anamorph, de Steven Miller (2007). Aqui o assassino arquiteta toda uma mise en scene das mortes, remetendo à uma cronologia representativa das diversas técnicas de anamorfose ao longo da história da arte. Além de fazer referência a diversas obras e artistas.
} 
da arte.

Giovanni Modica, autor do livro Sette note in nero di Lucio Fulci. Viaggio nel cinema della precognizione e del tempo, comenta em uma entrevista sobre a semelhança entre os filmes de Kershner e Fulci. Segundo o autor,

Além disso, Sette note in nero gritava vingança em vários aspectos: o baixo interesse do público no momento em que foi lançado e o sucesso que os filmes estrangeiros inspirados por ele o tornaram um caso único. Ninguém sabia a inspiração para filmes como Eyes of Laura Mars, nem mesmo no momento em que este filme americano foi lançado. Mas este é apenas um exemplo ...

Como sugere, Eyes of Laura Mars parece diretamente inspirado em Sette note in nero. Além do tema da parapsicologia, a arte é agente essencial da narrativa. Trata-se de um tópico bastante explorado no cinema de gênero dos anos 1970, bem como na literatura que o fortemente inspirou ${ }^{5}$. Embora Fulci tenha trabalhado com o tema do psíquico na extensão de sua filmografia (como vemos em Paura nella città dei morti viventi, Manhattan Baby, Voci dal Profondo, Aenigma, Demonia, Quando Alice ruppe allo specchio), nos interessa aqui a relação específica entre o cinema parapsicológico e a arte, pictórica ou fotográfica, majoritária em sua filmografia dos anos 1970.

Entre as imagens que acometem a protagonista de Sette note in nero, três carregam expressivamente referências ao mundo das artes plásticas. São elas, o espelho quebrado, cujos estilhados revelam a pintura do teto do antigo aposento de Francesco; a hodegétria da Teótoco ${ }^{6}$, presente na pequena igreja na qual Virginia esconde-se de Rospini; a reprodução d'A carta de amor (1669), de Vermeer com o endereço "Lombrone 6" escrito sobre.

Sua primeira visão, do espelho quebrado, é o afresco que decora o teto do aposento refletido apenas nos estilhaços. Em momento algum Fulci nos exibe a pintura superior do aposento. O ícone bizantino parece remeter diretamente ao espaço da igreja abandonada, filmada na Chiesa di San Biagio, em Sacrofano. Mas é em Vermeer que reside o mistério de Sette note in nero.

Em sua busca, Virginia e Luca (Marc Porel) descobrem o endereço da Pinacoteca Aldobrandi,

\footnotetext{
4 MODICA, Giovanni. Sette note in nero. Viaggio nel cinema della precognizione e del tempo. Morpheu Edizione, 2008. Tradução livre. Entrevista completa: "Intervista allo scrittore Giovanni Modica" IN Cineforum Imperia. Disponível em: http://www.cineforumimperia.it/file/cine_RUBRICHE/ rub_altro/libriecinema/settenoteinnero.html

5 Para citar apenas alguns exemplos que mesclam o gênero do suspense com a parapsicologia e sua presença massiva no cinema da década de 70: Don't Look Now (Nicolas Roeg, 1973) - adaptado do conto homônimo de Daphne du Maurier, The Eyes of Charles Sand (minissérie televisiva dirigida por Reza Badiyi, 1972). Na Itália, esse tópico é visto em filmes como: Profondo Rosso e seu apoteótico início com o congresso de parapsicologia, as visões psicodélicas de Valentina (Susan Scott), em La morte accarezza a mezzanotte (1972, Luciano Ercoli), As sessões de terapia hipnótica de Carol (Florinda Bolkan) e seus sonhos em Una lucertola con la pelle di donna (Lucio Fulci, 1971).

6 Obra que lembra em demasia a Madonna Kahn da National Gallery (figura 06).
} 

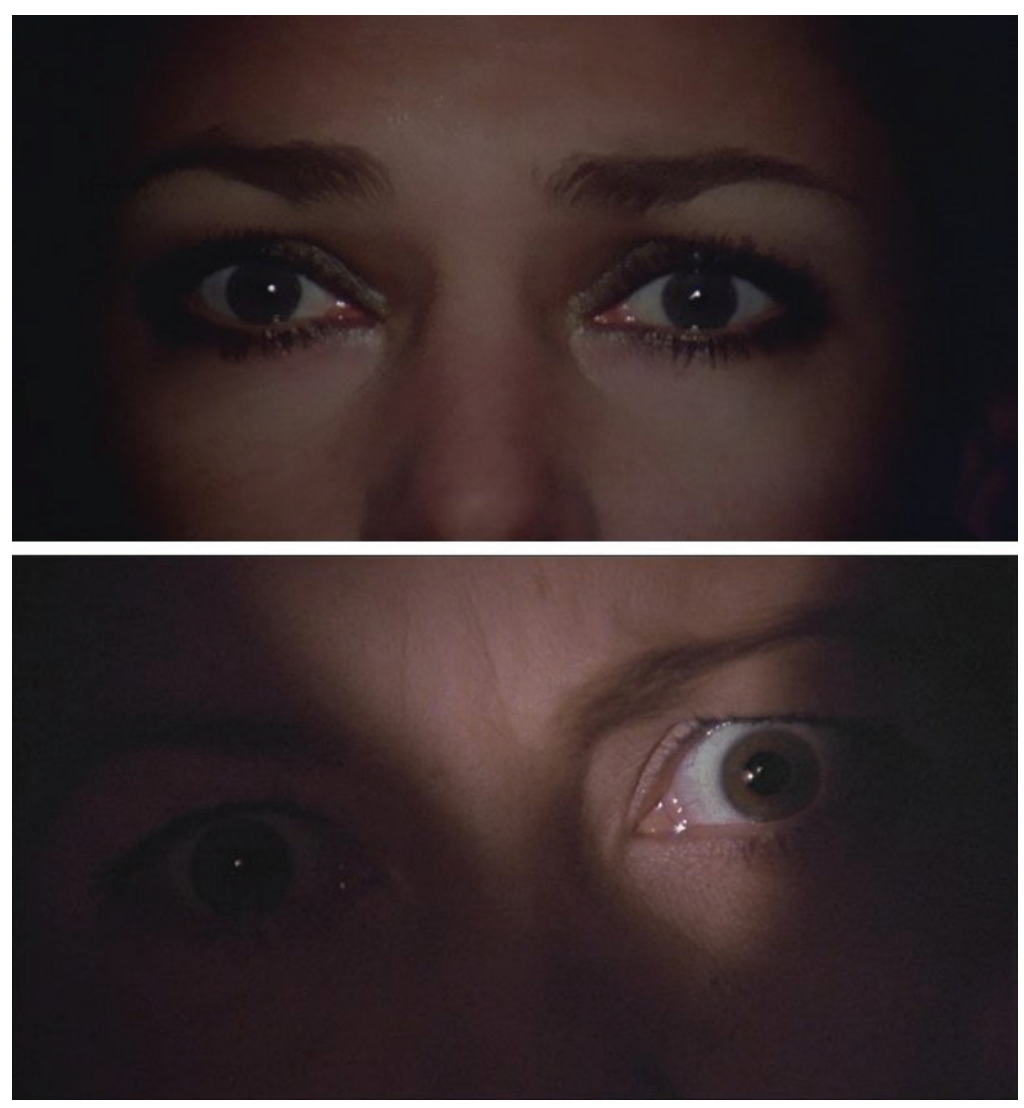

[Figura 03]

Comparação entre fotogramas de Sette note in nero e Eyes of Laura Mars
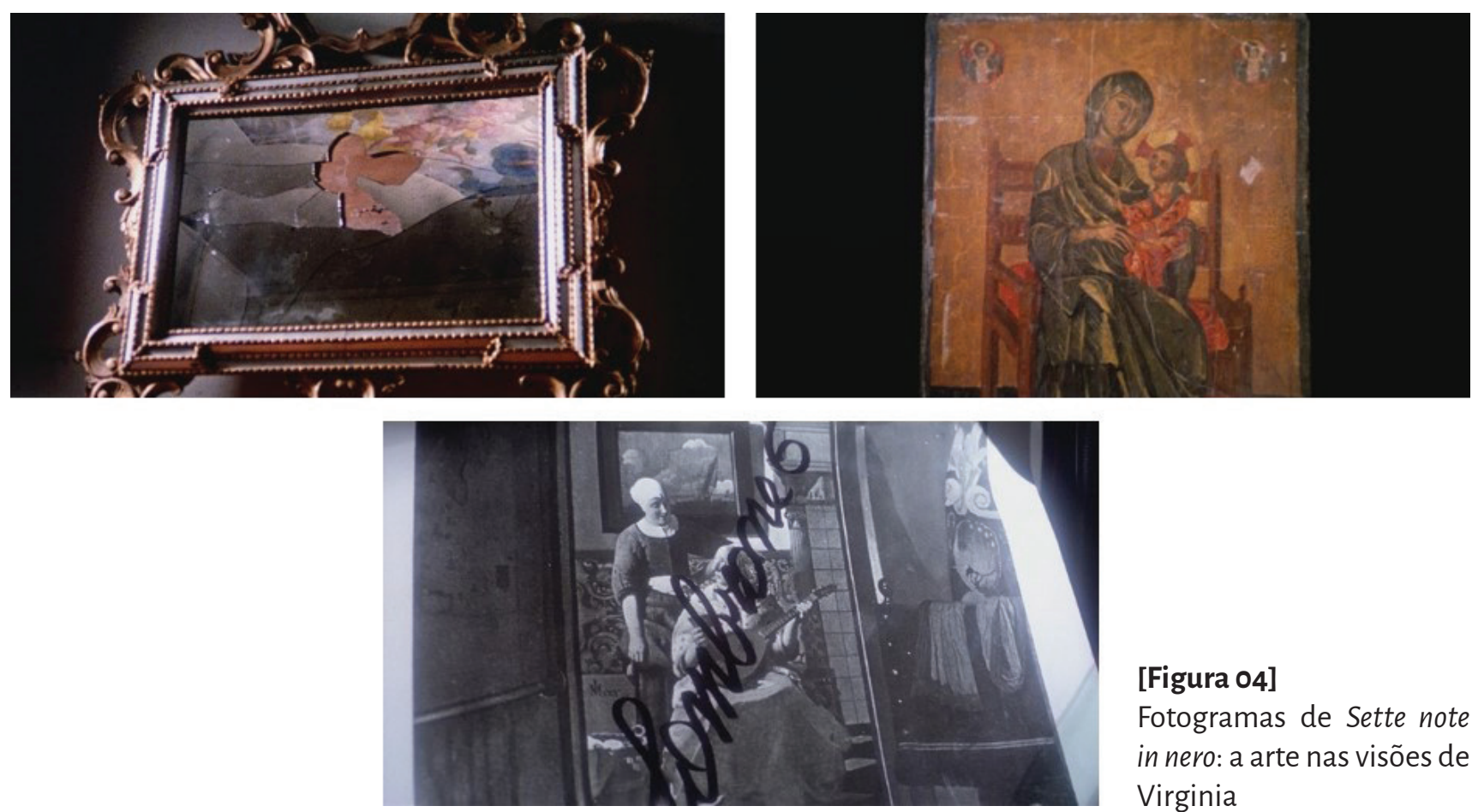

[Figura 04]

Fotogramas de Sette note in nero: a arte nas visões de Virginia 

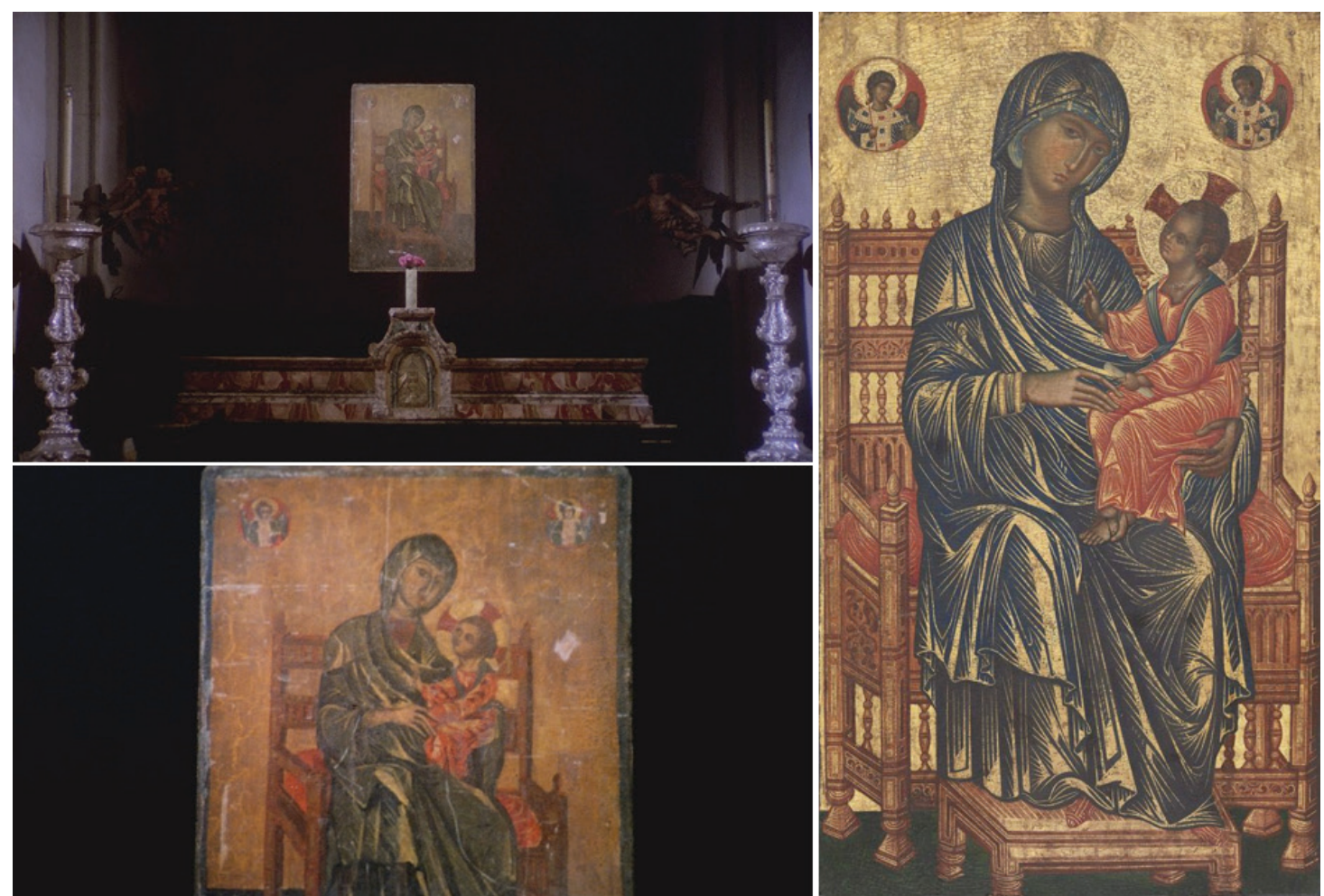

[Figura 05] Fotogramas de Sette note in nero, a hodegétria do filme (esquerda) e Madonna entronada com o menino c. 1250-75, têmpera sobre madeira. National Gallery of Art, Washington.

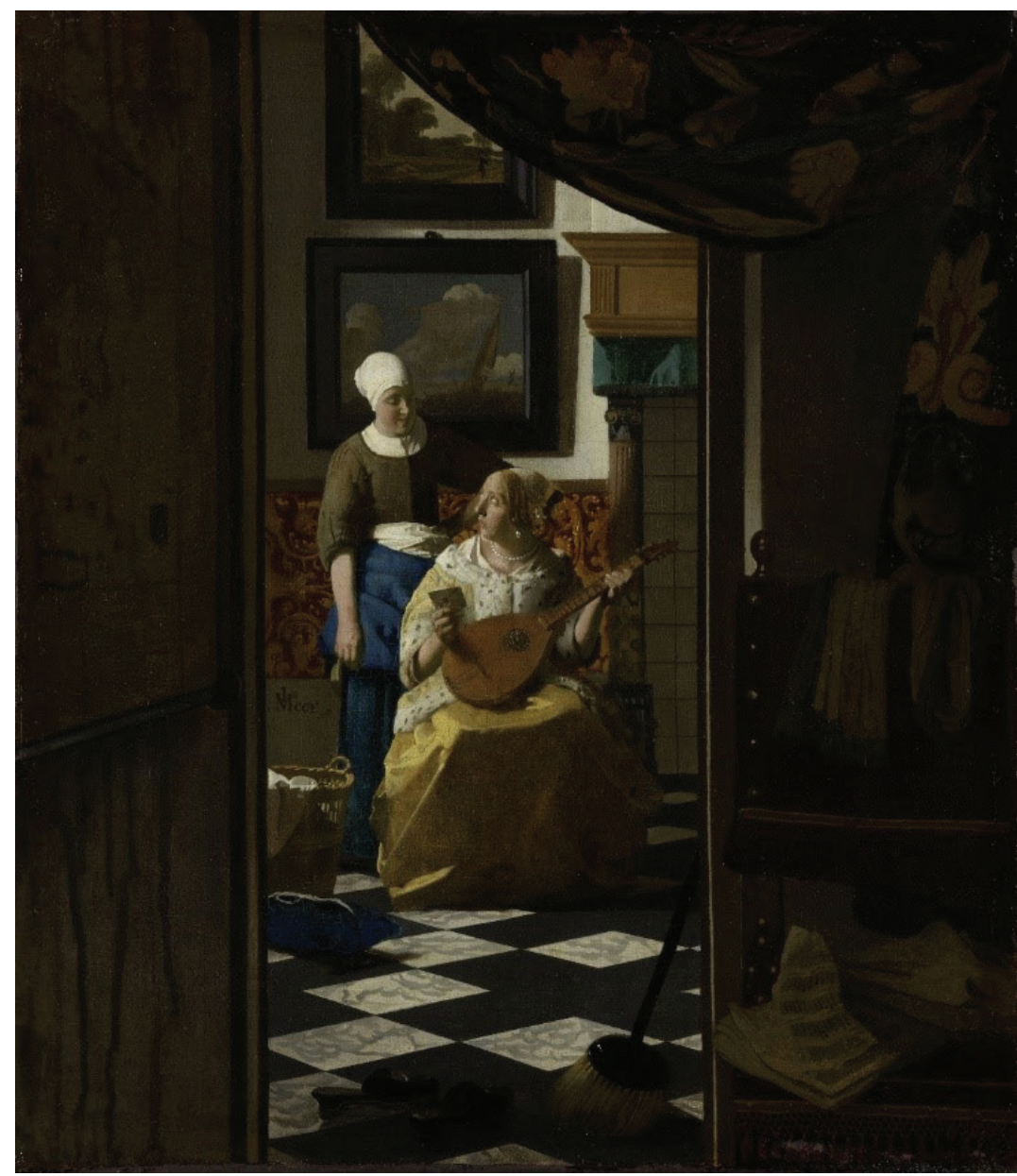

[Figura 06]

Johannes Vermeer. A carta de amor, 1669c. óleo sobre tela. Rijksmuseum, Amsterdã 

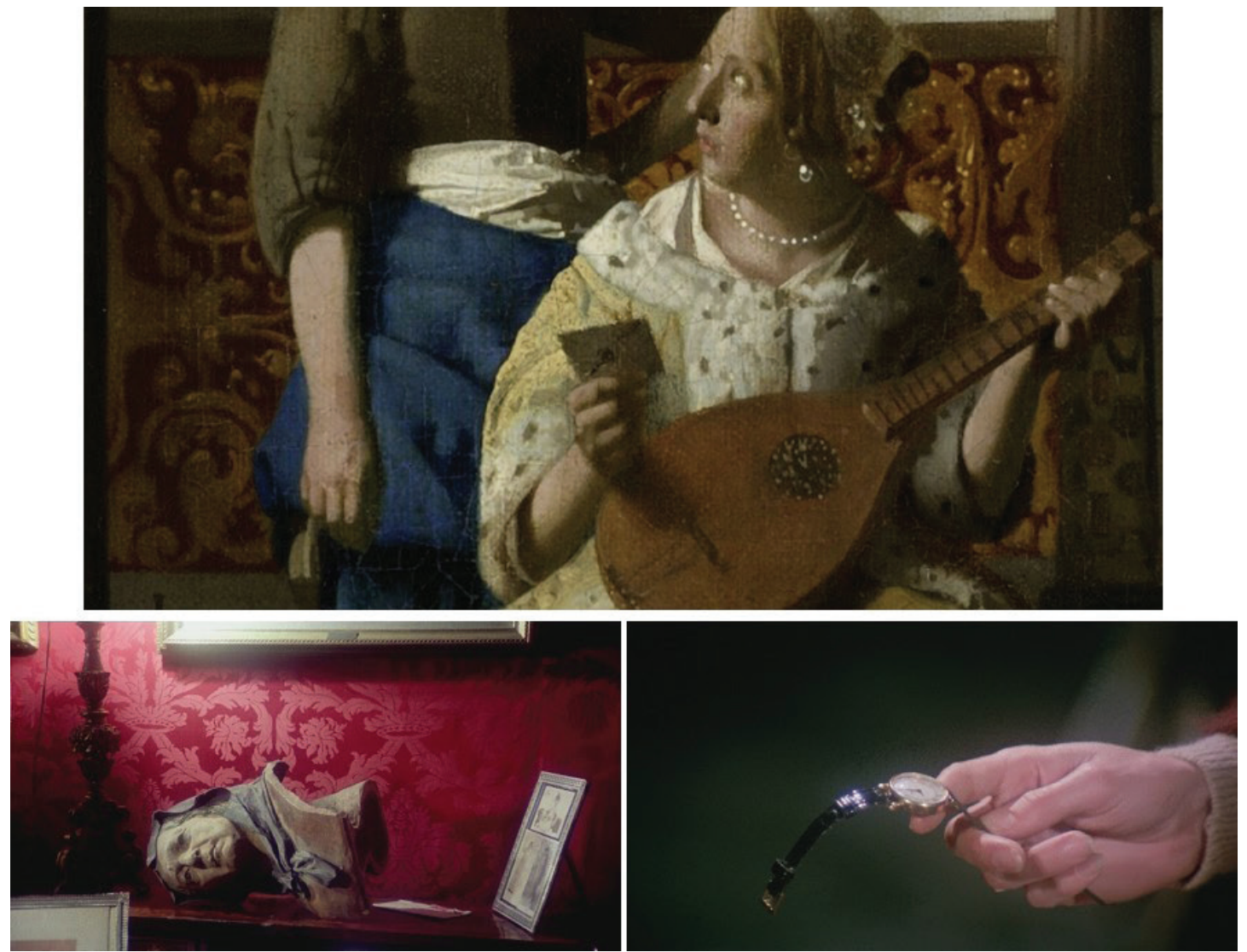

[Figura 07] os elementos de Vermeer presentes no filme em comparação a um detalhe de A carta de amor: a padronagem vermelha, a carta descoberta e a melodia do relógio.

local que possivelmente abriga a hodegétria que vira em suas premonições. Contudo, ao chegar no local, percebe uma reprodução semelhante daquela de Vermeer, com uma placa informativa acusando o roubo da obra em 3 de março de 1972.

Fato interessante é que o filme se encarrega de trabalhar acontecimentos contemporâneos à trama. A tela em questão, A carta de amor, parte da coleção do Rijksmuseum, em Amsterdã, fora emprestada para o Museu de Belas Artes de Bruxelas, para compor a exposição Rembrandt e seu tempo, que se estenderia de 23 de setembro de 1971 a 21 de novembro do mesmo ano. No dia de abertura da exposição, a tela foi roubada por Mario Pierre Roymans, que desejava como resgate um auxílio à população do Paquistão Ocidental, com o genocídio em Bangladesh. A obra foi enfim recuperada e Roymans sentenciado à prisão. Mas o tema do assalto não se restringiu apenas à referência ao roubo. No filme, os responsáveis pelo desaparecimento da obra foram Rospini, diretor da Pinacoteca, Francesco e a modelo Agnese Bignardi.

A obra, realizada pelo pintor holandês em 1669 tem como figura central uma jovem, que interrompe o momento musical ao receber a carta de um amante. A cena se concentra fora do pri- 
meiro plano, a qual observamos de um outro aposento, obscurecido, cuja porta que direciona para a cena principal exibe em sua lateral esquerda um mapa, presente em outras pinturas do artista tais quais Mulher lendo uma carta (c. 1662-65) e Soldado e moça risonha (c. 1658). A cortina, apoiada sobre a passagem, acentua o caráter voyeurístico da cena. Como intrusos, descartamos os elementos de perturbação do olhar, a vassoura, os tamancos sobre a abertura e flagramos o momento privado que parece condensar um universo próprio, o dos amantes, identificados através dos símbolos do amor (a paisagem marinha, a música e a melodia), bem como no gesto ingênuo da entrega da carta.

Fulci retraça os símbolos da composição de Vermeer no jogo dúbio das premonições, refletindo a mise en scène de $A$ carta de amor nos elementos-chave das visões de Virginia. O tema do assalto da obra, a traição de Francesco, a melodia do relógio reflete-se todos nos detalhes de Vermeer. A carta de amor reporta àquela do filme, escondida na base do busto da residência da Lombrone 6 , cujo aposento inclusive, recoberto pelo tecido de parede rubro, traz à mente o ornamento de tapeçaria presente na obra do pintor holandês. Vale lembrar ainda que a cena holandesa se transpõe no interior do outro aposento e igualmente Virginia se vê num espaço alheio à cena principal. Transforma-se na observadora silente e distante de seu próprio destino-revelado para ela na visão confusa, e posteriormente concretizado quando é emparedada viva pelo marido.

Os filmes aqui apresentados concebem um jogo intenso de relações com o objeto artístico - fotografia ou pintura. São produções que trabalham sobre aspectos completamente diversos das artes e que, no entanto, compreendem-no em sua totalidade. De um lado, em Eyes of Laura Mars as imagens parecem aludir ao comportamento de caça e caçador entre Laura e o assassino. A utilização das fotografias de Blake e Newton mostram o apreço pela cultura contemporânea, às artes, em específico àquelas relacionadas à moda. O filme parece completamente imerso na atmosfera das fotografias ${ }^{7}$.

A incorporação dos elementos iconográficos de A carta de amor em Sette note in nero, por sua vez, condensa as diversas pistas da premonição, como ocorre também nos filmes de Dario Argento, tudo está contido no interior da imagem. Como o historiador da arte que se debruça sobre os detalhes de uma composição, identificando seus signos e significados, cabe a Virginia desvendar os caminhos das imagens. Cada qual a sua maneira, esses filmes trabalham de modo a perceber a imagem, seja como resquício ou representação, seja como construção de uma verdade. 


\section{Referências filmográficas e bibliográficas}

EYES OF LAURA MARS (Os olhos de Laura Mars). Irvin Kershner. EUA: Columbia Pictures, 1978. 124 min.

SETE NOTE IN NERO (Premonição). Lucio Fulci. Itália: Rizzoli Film, Cinecompany, 1977. 95 min.

BALUN, Chas. Lucio Fulci: Beyond the gates. Florida: Fantasma Books, 1997.

BRUSCHINI, Antonio; TENTORI, Antonio. Lucio Fulci - il poeta della crueltà. Il cinema gótico e fantastico italiano vol. 8. Roma: Profondo Rosso, 2004.

CURTI, Roberto. Italian gothic horror films, 1970-1979. Carolina do Norte: McFarland \& Publishers, 2015.

GRISERI, Carlo; FRASSINELLI, Marco. "Intervista allo scrittore Giovanni Modica" IN Cineforum Imperia. Disponível em: http://www.cineforumimperia.it/file/cine_RUBRICHE/rub_altro/libriecinema/settenoteinnero.html

LUPI, Gordiano. Storia del cinema horror italiano. Da Mario Bava a Stefano Simone vol. 2 - Dario Argento e Lucio Fulci. Itália: Ass. Culturale II Foglio, 2011.

THROWER, Stephen (org.). Eyeball Compendium - Writtings on sex and horror in the cinema from the pages of Eyeball Magazine, 1989-2003. Surrey, 2003

Beyond Terror: The films of Lucio Fulci. Codalming: FAB Press, 2002.

WALLER, Gregory Albert. "Eyes of Laura Mars: A binocular critique" IN American Horrors: Essays on the Modern American Horror Film. Illinois: University of Illinois Press, 1987. pp. 62-78 